\title{
Adorno's Praxis of Individuation Through Music Listening
}

Jeremy J. Shapiro*

(Fielding Graduate University)

\begin{abstract}
Theodor W. Adorno's Anweisungen zum Hören neuer Musik (Guidelines for Listening to Modern Music) contain instructions not only for how to listen but also for how to have experience in general. The psychological, perceptual, and cognitive structures involved are existential structures, i.e. guidelines as to how to be as a modernist or post-modern self. Since listening involves abandoning oneself to the immanent logic of musical works, it is these works that provide the model for how to be. Adorno's work also shows, in contradistinction to some views of Adorno, his commitment to the unity of theory and practice and demonstrates that his musical writing is a completely independent and novel strand of critical theory because of its attempt to articulate the ineffable. However, Adorno's explicit theory of listening ("structural listening") is itself inadequate to Adorno's implicit theory of listening as contained in the practice of his actual musical writings.
\end{abstract}

Keywords: Adorno; music listening; modern music; individuation; ineffability.

\footnotetext{
* Dr. Jeremy J. Shapiro is professor of human and organization development at Fielding Graduate University. He is the co-author of Mindful Inquiry in Social Research and of papers on the social, cultural, and psychological impact of information technology and systems and on critical social theory. A student of Adorno (and of Marcuse and Habermas) and a translator of some of their works into English, he is particularly interested in the aesthetics of music and the phenomenology of music listening, and is currently translating into English some of Adorno's essays on listening to music. He resides in New York City.
} 
A number of years ago TV Guide, which millions of Americans use to select which television programs to watch, published a cartoon in which two housewives, with their hair in curlers and dressed in housecoats, are sitting and watching television. One housewife says to the other: "The trouble with real life is it doesn't have any plot."

This cartoon captures something fundamental about the relationship between the realities of lived experience on the one hand and culture on the other. Culture - every culture - provides its members with ready-made plots that determine or shape how they/we organize, make sense of, and interpret their/our "real life". In modernity in particular, this relationship is dialectical, in that modern society valorizes individuality, defined as that which goes beyond the plots already available, and individually lived lives can have a certain impact on these plots, extending, revising, and in certain cases replacing them. At the same time, the plot industry of culture, attempts to absorb any transcending, innovative, or deviant life into itself. Part of post-modern consciousness is the awareness, perhaps even among ordinary people, i.e. people who have never heard of post-modernity, of the arbitrary and constructed nature of the plot repertoire and of the disjunction between "real life" on the one hand and plots on the other. This disjunction is amplified by the weakening or collapse of "grand narratives" - of religious, ideological, or symbolic meaning schemes that served as pre-given plots for so many for so long, despite the reactive resurgence of such narratives in the world at the present time. In his address for the centenary of Mahler's birth, Theodor W. Adorno wrote of the

perception that the Western idea of unified, internally coherent, as it were systematic music, whose unity is meant to be identical with its meaning, is no longer viable. It has become incompatible with a situation in which people are no longer in command of any authentic experience of such a meaning in their lives. It is incompatible with a world which has ceased to provide them with the categories of unity in happiness, leaving them only with those of standardized compulsion. (1992b, p. 92) 
In other words, "the trouble with real life is it doesn't have any plot" - or at least none that provides, unity, meaning, or happiness. Adorno would surely have found of interest, but not surprising, the emergence of "reality television", which supposedly portrays "real life", thus pretending to overcome the disjunction between the two realms, but only by providing the real life with plots - and ones that certainly could be described as "standardized compulsion".

A central focus of Adorno's work is the dichotomy and divergence that came into existence in the early 20th century between two forces. The first was the emergence of the culture industry as one devoted to the production, distribution, and inculcation of a repetitive set of manufactured plots - indeed of "plotness" - what Adorno refers to as the "always-the-same" (das Immergleiche) as the essence of the controlled ideological consciousness that robs individuals of freedom. The second was the emergence of modernist art, especially music but also literature and painting, as the project of developing, expressing, and representing a consciousness that is freed from plots or, to use a recurring term in Adorno, from "schemata". The present essay is an expansion and application to music-listening - with emphasis on modern music - of Shierry Weber Nicholsen's exposition and interpretation of Adorno's aesthetics in her Exact Imagination, Late work: On Adorno's Aesthetics, where she writes that

if his work emphasizes the withering of the capacity for individual experience in an administered society that preforms experience - which then only seems to be individual subjective experience, in the sense that it gives the illusion of a constitutive subjectivity - at the same time, the aesthetic dimension of Adorno's work holds out, and indeed is premised on, the possibility of a valid, that is "adequate" or "authentic", subjective experience. This genuine subjective experience is the correlate of the primacy of the object and the condition for non-discursive knowledge of the object. (1997, p. 4)

Authentic or adequate listening to modern music involves precisely genuine subjective experience that is the correlate of the primacy of the object and a nondiscursive knowledge of the object. According to Adorno, an authentic work of modern music is something entirely individual that has left behind any traditional 
musical schemata of organization and is organized entirely through a unique set of internal relations. In his essay Vers une musique informelle he summarizes this idea as a normative model for composers:

What is meant is a type of music which has discarded all forms which are external or abstract or which confront it in an inflexible way. At the same time, although such music should be completely free of anything irreducibly alien to itself or superimposed on it, it should nevertheless constitute itself in an objectively compelling way, in the musical substance itself, and not in terms of external laws. Moreover, wherever this can be achieved without running the risk of a new form of oppression, such an emancipation should also strive to do away with the system of musical co-ordinates which have crystallized out in the innermost recesses of the musical substance itself. (1992d, p. 272f.)

Accordingly, to listen to and understand such music requires a corresponding form of musical consciousness that has freed itself from or gone beyond these schemata and external or abstract forms and is thus, in a way, an individuated analogue of the musical work itself. It is worth noting that focusing now on Adorno's approach to listening from almost a half-century ago fits within a larger order of the present day, namely a recent upsurge in interest in and thinking about listening from the perspective of both philosophy (Levin, 1989; Nancy, 2002) and musicology with a focus on actual listening processes (Clarke, 2005; Clifton, 1983; Cook. 1990). This is of course paralleled by a resurgence of interest in Adorno's own approach to music (Paddison, 1993; Leppert, 2002; DeNora, 2003).

Adorno is often thought of as an analyst, theorist, and critic without orientation or commitment to praxis in the traditional Marxist sense and even as opposed to it. His colleague Herbert Marcuse once called him "the last great bourgeois philosopher" (Marcuse, personal communication, 1964). I have no intention here of reviewing the controversies about this. Rather, I want to focus on an area where Adorno involved himself acutely in praxis - the practice of performing and listening to music. In the preface to Der getreue Korrepetitor: Lehrschriften zur musikalischen Praxis ("The faithful coach: instructional writings for the practice of music") he writes, 
in the theory supported by the author, the transition to possible praxis does not occur by having the latter having to subordinate itself to theory. Precisely through undiluted logic it leads to instructions; at the same time it lives from experiences that cannot be obtained except in praxis. (1963b, p. 9)

In other words, experience is the mediator between theory and practice, is essential to the dialectical development of theory and of practice. Adorno's commitment to praxis is clear. One of my subsidiary intentions here, even though I will not pursue it as a theme in itself, is to rehabilitate Adorno as a critical theorist committed to practice and to the integration of theory and practice.

In the present paper I will illustrate this primarily with reference to Adorno's "Guidelines for Listening to Modern Music" (Anweisungen zum Hören neuer Musik, 1963a) because it is a rich source of concrete material about nonschematic or post-schematic consciousness and experience. I will also draw on a few related essays of Adorno (especially 1963c and1984). In the "Guidelines", originally given as a lecture with musical examples. Adorno identifies what he considers requisites for listening to modern music. They consist especially of a set of dialectical "unities of opposites" that, together, Adorno labels "structural listening" (1963a, p. 95; 1963c, p. 34-37), although a number of them are not directly related to matters of musical structure in the conventional sense of that term.

Prominent among these oppositions are the ability to respond to each moment without expectations, but also to perceive how the musical notes in the present lead almost inexorably to the new moment; to be simultaneously in a state of heightened attention and concentration on the one hand and of surrender or self-abandonment to the movement of the music on the other; to listen in a way that is enriched by analysis but at the same time consciously oblivious of analysis during the listening process; to be both responsive to unconscious and chaotic impulses while attuned to highly structured ordering principles; to be fully in the present moment but able to link and integrate past, present, and future; to be simultaneously naive, with no need of musical expertise, and yet to have what some would consider musical sophistication; and to have the listening version of the Hegelian "insight [...] that there is no non-identity without identity, nor the 
latter without the former" (Adorno, 1963a, p. 50f.). While these traits are exemplified in terms of musical material, they can also be looked at as a model for a new kind of subjectivity that is capable of having authentic experience and penetrating the mystifications of false consciousness present in music in particular but also in contemporary mass culture in general.

I would argue that Adorno's guidelines for listening to modern music were important to him because he saw false consciousness in music as a kind of glue that held general false consciousness together, such that learning to listen to individuated, non-schematic music was a key weapon, as it were, in the struggle against false consciousness that has always been a primary focus of both classical Marxism and Frankfurt School critical theory. This role of music in false consciousness may not have been significant in pre-industrial, pre-mediated society, but with the musical saturation of life by the culture-industrial production of popular music and its distribution through the mass media, which Adorno started to study seriously around 1940 and which intensified and increased geometrically during his lifetime and even more so since his death, music has become the permanent elevator music and the permanent beat that accompanies all of our lives, the cultural amniotic fluid in which we float and which people use daily to shape their identities and decorate their life-worlds (DeNora, 2000). Hence learning to listen to modern music as a way of having individuated experience has only grown in significance in the almost half-century since Adorno's lecture and thus lends greater import to his contribution to practice. It is why Adorno asserts that "modern music can be considered the bearer of a spiritual and moral obligation" (1963a, p. 96).

In this paper I am making three primary and three subsidiary claims:

The first primary claim is that, because of this key function of music in contemporary life and consciousness, Adorno's "Guidelines" have implications beyond musical experience itself: that indeed they can be looked at as guidelines for how to perceive or how to have experience in general. For the psychological, perceptual, and cognitive structures involved in listening to modern music are general characteristics of broader application. 
The second primary claim is that these mental and experiential structures are not merely about perceiving or experiencing but are really existential structures - that is, I would argue, Adorno's guidelines for listening are not merely guidelines for perceiving or interpreting but also guidelines as to how to be. It is striking that the language Adorno uses to describe listening includes such terms or phrases as "being in the music" (1963a, p. 39), which designate not psychoauditory traits but existential ones. Since Adorno wrote in Minima Moralia (1951) that the subject has been liquidated, his guide to listening is in effect a guide to how be a subject when the subject has already been liquidated, as suggested by Nicholsen's words, quoted above, about the possibility of valid subjective experience.

The third primary claim is that, since listening involves abandoning oneself to the immanent logic of musical works, it is ultimately these works themselves that are really the guide to how to be - if one knows how to listen to them. As Adorno writes, "The more organized and integrated the music, the more rigorously it relates all of its elements to one another, the more it integrates the listener, the less it leaves him out" (1963a, p. 41). This appeal to musical works as themselves providing integration or identity for the listener is in keeping with the key theme of Adorno's later work, der Vorrang des Objekts, the primacy of the object, as a reversal of and protest against the dominating subject of repressive Western civilization (Adorno, 1970).

The subsidiary claims are about Adorno's work itself. The first is the one I have already introduced about Adorno's commitment to the unity of theory and practice, with the transformation of musical experience, and aesthetic experience more generally, as its focus. The second, which I shall discuss below, is that Adorno's musical writing is a completely independent and novel strand of critical theory whose theoretical status has not been clearly recognized. The third, which I shall adumbrate in the concluding section, is that Adorno's explicit theory of structural listening does not adequately account for Adorno's implicit theory of listening as contained in the practice of his actual musical writings. For it captures 
only one or two dimensions of a much more multidimensional approach for which "structural" is not the most apt term.

Why should music be such an important example of the primacy of the object? Perhaps in no other domain does this notion arise as distinctively and as poignantly as in that of music, because in an emphatic sense, despite certain similarities between music and language that Adorno discusses in his brief essay on their relationship, music is in a strict sense so far beyond language, outside of language, "other" to and other than language, that it can stand as the paradigmatic case of that which transcends the subjectivity that is manifested in language (which can be roughly equated to the realm of the conscious in a psychoanalytic sense). Of course music does this in a metaphysically ironic sense, because "music resembles a language" (1992c, p. 1) and is at the same time, through and through, subjectivity, even though at the same time it is outside of and resistant to language. So music is both subject and object, both language and non-language. This is central to Adorno's statement that "works of art are the only things-in-themselves" (1963c, p. 38). In this he goes even beyond Schopenhauer, who, while maintaining that music "represents the metaphysical in relation to everything physical in the world, the thing-in-itself in relation to all appearance" (Schopenhauer, 1859, p. 353), nevertheless claimed only that music represents the thing-in-itself, not that music itself possesses that status. As Adorno says of the meaning of music, it "is not to be understood as something represented by the music or expressed by it: it has absolutely no existence independently of the music but is rather, again according to Schoenberg, something that can be said only through music" (1984, p. 689). This means that all writing about and analysis of music is afflicted with paradox, selfcontradiction, self-negation, and indirection, since it tries to say something in words that in fact can be said only through music.

The ineffability of music is not only a fundamental issue in the philosophy of music but, if music has meaning, arguably raises important issues for the philosophy of language and meaning, with both epistemological and ontological implications. Stated most simply, it seems obvious that music has 
meaning: but no-one can say exactly what it is, or agree on what it is. It does not denote anything. It has been treated as meaningful in its own terms not only by Adorno but also by such philosophers of music as Suzanne Langer, Vladimir Jankélévitch and Laird Addis (Addis, 1999; Jankélévitch, 2003; Langer, 1953). As far as I know, the issue of ineffability and its place in the relation of music and language was first most profoundly articulated in the modern period by Mendelssohn, who complained that words

seem to me so ambiguous, so indefinite, and so easily misunderstood in comparison with genuine music, which fills the soul with a thousand things better than words. The thoughts which are expressed to me by a piece of music that I love are not too indefinite to be put into words, but on the contrary too definite. (Mendelssohn Bartholdy, 1878, p. 221)

The non-linguistic, non-conceptual character of music highlights the importance of the effort nevertheless made by Adorno to undertake the Hegelian "exertion of the concept" in being able to say something insightful and instructive about what is unsayable. A critical theory that could not speak meaningfully and in depth about music, about the unsayable, would not be a complete critical theory certainly not one that could account fully for the different forms of consciousness, both true and false, both conscious and unconscious.

Indeed in this way Adorno's musical work can be understood as a radical, qualitatively different complement and parallel to the incorporation of the psychoanalytic dimension into critical theory. On the one hand, both attempt to explain and interpret meanings that are unconscious and that help explain such sociopolitical phenomena as fascism, the authoritarian personality, and the liquidation of individuality. On the other hand, at least from the Freudian perspective that has been central to critical theory, the unconscious consists of meanings that have been repressed and become inaccessible to awareness and linguistic formulation but are in principle capable of recovery and linguistic formulation, either through clinical psychoanalytic processes or through theoretical interpretations. As we know, Habermas's use of psychoanalysis as 
paradigmatic for critical knowledge is based on the model of the linguistic banishment and re-appropriation of meanings - replacing private meanings and symbols with public language (Habermas, 1971). But, as we have seen, the meanings manifested in music are in principle incapable of linguistic translation and direct linguistic formulation. Thus Adorno's music-analytical oeuvre represents a fundamentally different theoretical and practical strategy than the psychoanalytic, attempting, as it does, to recuperate for critical theory the realm of the ineffable, both conscious and unconscious, with implications for both theory and practice. Whereas critical theory is sometimes thought of as captured in the equation "critical theory = Marx + Weber + Freud + Nietzsche", Adorno's work shows that a more accurate equation would be something like "critical theory $=$ Marx + Weber + Freud + Nietzsche $+x "$, where the $x$ could be understood to stand for the stream of thought from Mendelssohn to Schoenberg and Adorno (and continued by Jankélévitch and others) that highlights the ineffability and centrality of music and the ineffable in experience in general. Nietzsche himself, incidentally, also asserted that the meaning of music was ineffable, but that is not the usual context in which he is considered tributary to the Frankfurt School.

In Exact Imagination, Late Work, Nicholsen defends Adorno precisely on these grounds against Habermas's and Wellmer's critique of him from the perspective of a communication theory of society. As she writes, "Adorno's work transcends Wellmer's attempted Habermasian reconstruction precisely because that reconstruction relies on a premature equation of the subjective with the linguistic or communicative" (1997, p. 6). It should be noted as well that in this regard Adorno's thinking intersects with current research from an evolutionary perspective about the origins of and relation between music and language. Thus some contemporary scholars advance the theory (which originates with Rousseau, 1996 [1781]) that music and language are separate, specialized evolutionary branches that derive from a common root, a "musilanguage" that preceded them (Brown, 2000), and that music is as constitutive of humanness as language (Mithen, 2005; Wallin, Merker and Brown, 2000). Most of those working within 
this approach think of music as something that conveys or represents emotion and promotes social bonding and of language as something that conveys or represents information, although the representation of emotion is sometimes conceived in a rather limited sense that does not account for the almost infinite variety and specificity of what is conveyed by musical works, which exceed by far any recognized repertoire of emotions. Addis certainly has a more adequate and finegrained theory, asserting that music represents emotions, moods, sensations, and "possible states of consciousness", including "moods, emotions, and other frames of mind that, as far as we know, have never been experienced or even conceived" (1999, p. 78). But this re-evaluation of the role of music in society undermines the social science truism of past generations that language and tool-making alone are the differentia specifica of homo sapiens. It may require that the communication theory of society be replaced by or supplemented with a musical one.

The affliction by paradox and self-contradiction of writing or talking about the ineffable in music also explains why the intellectual effort of doing so has a kinship with mysticism in its attempt to conjure a unity with the ineffable: in Adorno's mystical description,

The language of music is quite different from the language of intentionality. It contains a theological dimension. What it has to say is simultaneously revealed and concealed. Its Idea is the divine Name which has been given shape. It is demythologized prayer, rid of efficacious magic. It is the human attempt, doomed as ever, to name the Name, not to communicate meanings. (1992c, p. 2)

Indeed, Adorno asserts that it has been impossible to discover what music authentically is. Thus writing about music may involve conceptual articulation, but it can do so fruitfully only in combination with two other strategies. The first is pointing to that in the music which is beyond such articulation, i.e. through "ostensive definition." That is why, for example, when Adorno wants to "explain" and demonstrate this unsayable musical meaningfulness, he does so by playing music (in a lecture with piano), that is by playing the same musical phrase from Bach twice, once unphrased and unarticulated and once with phrasing and 
articulation. "Only the second time will it be meaningful" (1984, p. 689). The proof will be in the hearing, not in a proposition about it. As Adorno writes in his essay on music and language, "to interpret language means: to understand language. To interpret music means: to make music" (1992c, p. 3).

Adorno's second strategy is the use of figurative language, as Nicholsen has emphasized in her work: the use of images, metaphors, and associations, to capture the essence of that which cannot be defined conceptually (1997, p. 26). This may be linked to the intimate relationship between music and metaphor: it has been argued that, in the context of the evolutionary emergence of the human species, "music [...] can sustain the emergence of a metaphorical domain, acting to create and maintain the cognitive flexibility that appears to be the hallmark of our species" (Cross, 2003, p. 27). Since the use of figurative language is an attempt to capture the ineffable, then, once we have recognized that capturing the ineffable is essential to critical theory, we can see that figurative language is not a mere personal style of Adorno but rather is essential to critical theory per se. Stated in other terms, a hermeneutic of imagination and indirection is inherent in critical theory to the extent that it attempts to penetrate to the pre-, non-, sub-, and extra-linguistic dimensions of human experience and society (see also Kramer, 2003). For those who are not directly familiar with Adorno's use of figurative language in the description of music, I cite a lengthy but rich example from his comments on Der Abschied ("The Parting"), the last movement of Das Lied von der Erde ("The Song of the Earth") in his book about Mahler:

To the work [The Song of the Earth] the earth is not the universe, but what fifty years later could fall within the experience of one flying at a great altitude, a star. For the gaze of music that leaves it behind, it is rounded to a sphere that can be overviewed, as in the meantime it has already been photographed from space, not the center of Creation but something minute and ephemeral. To such experience is allied the melancholy hope for other stars, inhabited by happier beings than humans. But the earth that has grown remote to itself is without the hope the stars once promised. It is sinking into empty galaxies. On it lies beauty as the reflection of past hope, which fills the dying eye until it is frozen below the flakes of unbound space. The moment of delight before such beauty dares to withstand its abandonment to disenchanted nature. That metaphysics that is no longer possible becomes the ultimate metaphysics. (1992a, p. 154) 
I emphasize the paradox of writing about the ineffable in order to frame Adorno's project of using language to make modern music understandable and point to its inherent difficulties and limitations, which is one of several reasons that the concluding paragraph of Adorno's "Guidelines" begins, "Admittedly, the value of all these suggestions is questionable" (1963a, p. 97). As I have already suggested, it is because of this resistance of music to being grasped linguistically that it can serve as a model for thinking about how to perceive and how to have experience in general: precisely because it is a limiting case, it can stand for all that in lived experience which is below the threshold of linguistic and conceptual unrepeatability. But since much of our life is at that level - more than we usually can acknowledge to ourselves and to others - it seems worth pursuing the idea that learning to listen to modern music can be a vehicle for learning to listen both to ourselves as modern/post-modern individuals and to the modern/post-modern world that we inhabit - as well as to the music, culture, and experience of the past.

That Adorno conceived the appropriate way to listen to modern music as of broader extension, as not just some limited, technical way of providing access to the avant-garde, can be seen in his very strong claim "that every piece of music since the beginning of the common practice period (Generalbasszeitalter) [in other words, since the mid-17th century - JJS] should be listened to as though it were modern" (1963c, p. 35). That is because, despite being composed within traditional schemata, the great works of traditional classical music were already, in themselves, underneath these very schemata, although often in a concealed way, organized entirely through a unique set of internal relations, or, to use Adorno's words quoted above, "constituted [...] in an objectively compelling way, in the musical substance itself, and not in terms of external laws." This internal tension or contradiction between internal formal organization and the schematic shell that houses it is central to both Adorno's aesthetic conception and his own aesthetic perception and is what he denotes with the term "the subcutaneous", a term that he himself attributes to Schoenberg: "I believe that this concept of subcutaneous form holds for all music of true greatness in all of its aspects" 
(1984, p. 688). And "you have only understood [a traditional musical work] when you succeed in pursuing and knowing in detail what actually unfolds musically beneath [the schemata] [...]. Only then have you heard what is concretely happening in the music" (1984, p. 688).

What has happened in modern music "is in truth only that the subcutaneous, i.e. the fabric of individual musical events as the bearer of a unified meaning, breaks through the surface, becomes visible, and asserts itself free of any schema. The inner becomes outer" (1984, p. 690) - a formulation that recalls the self-transformation and reconstruction of the subject in psychoanalysis. But it is only the transformation of perception involved in listening to modern music that makes it possible to truly and authentically listen to - to hear what is occurring in - its forebear, traditional music: to hear, for example, as Adorno tries to show, that Beethoven and Schoenberg used similar principles of organization (1984, p. 691-693).

These ultimately Hegelian conceptualizations, according to which what existed "in essence" finds its true, fully self-reflective and conscious form only in "the concept", that dialectical thought moves from the "abstract" (schematic) to the "concrete" (internally self-organized), and that history can thus only be understood backwards should now make clear the intent of the present argument. If music is indeed the glue that holds together false consciousness, and learning to listen to modern music is what enables the true understanding not only of contemporary music but of the music of the past, then it is also of strategic importance in attempting to arrive at a truer consciousness in the broadest sense. Learning to hear, to perceive, to understand the subcutaneous is an essential part of a dialectical approach that integrates theory, practice, and experience. In other words, learning to listen to and understand modern music is, as suggested earlier, not merely about expanding one's realm of musical enjoyment - it is also about developing a truer and deeper and more critical understanding of self and society. It is not enough to be able to think critically; one must also be able to experience critically, and thus to listen critically. Indeed, in this view, only if one can listen critically can one fully think critically. This does not mean, it should be added, 
that the deaf cannot experience or think critically, since the distinctions and analyses that Adorno puts forth apply in other aesthetic domains. Indeed, at one point he goes so far as to say that, because the arts are drawing closer to one another, "it could be proposed that one should listen to modern music the way one looks at a painting as a whole, grasping all its aspects at once" (1963b, p. 96). But as a temporal art, music is paradigmatic for consciousness in general. The temporal isomorphism between sound and consciousness is Addis's fundamental argument for music's ability to represent states of possible consciousness (1999, p. 66-69).

In the present context I will focus on just a few of the characteristics that Adorno highlights as essential to listening to modern music but that have implications for experiencing and thinking critically in general.

The first, in line with the notion of the primacy of the object, is about escaping from the constraints imposed by the rigidities of one's own subjectivity by giving oneself over to, perceiving, experiencing, and understanding the object itself. Here are some typical formulations: "the listener must completely abandon himself to what comes next. He cannot simply draw analogies to what he has already heard" (1963a, p. 45). "The logic of events speaks purely for itself" (p. 45). Listening involves "pure surrender to what is occurring in the music" (p. 53), hearing "where the sound itself, i.e. where each note that it contains, wants to go" (p. 55). "Entering into music and actively following it in its course means succeeding in the subject's abandoning itself to something that thereby becomes its own: anticipation of a state in which alienation has been eliminated" (1963c, p. 38). In other words, taken to the limit, adequate or correct or appropriate listening is an aesthetic orientation that, through transcending the subject toward the object and trying to follow the object in its own contours and configuration tends toward utopia. Thus someone who learns to listen to modern music is preparing herself or himself to understand reality as it really is, and this aesthetic education, as Schiller indicated so long ago, is thus also a kind of political education. 
The second characteristic has to do with the configuration or structure of reality itself. Adorno argues for the need for "the most intense concentration while listening" on the grounds that in modern music "everything is of equal importance, equally close to the center. Because nothing is external or accidental to the constitution of musical meaning, everything must be drawn into the field of attention, if the musical meaning is not to be missed" (1963a, p. 92f.). Thus the surrender of the self to the object is not to be a vague romantic swimming in an ocean of feeling but rather requires a precision and complexity corresponding to the precision and complexity that exists in the object. Adorno reminds us that in the great and paradigmatic works of modern music, the different, separable dimensions according to which music is traditionally conceived - melody, harmony, rhythm, timbre, texture, etc. - no longer exist as separate dimensions: "in the most sublime musical style of the present, that of Anton Webern, relations between color, texture, and the most minute motifs function to constitute the form" (1963a, p. 93). So the listener must achieve "a kind of synthesis of the most diverse elements and musical dimensions [corresponding] to the integration that occurs in composing itself" (p. 93). In other words, Adorno is proposing a new sort of synthesis in the subject that is required by the nature of the modern object: clearly the musical object, but, I would argue, also the modern object in general.

Two other aspects of the configuration or constitution of the object also enter into the kind of mixture of receptivity and synthesis required of the subject: the structure of time and the relation between instinct and chaos on the one hand and the order of formal construction on the other. With regard to time, the modern music of which Adorno speaks dispenses with repetition and is organized through the principle of "radical variation", which requires "recognizing the non-identical as nevertheless identical" (1963a, p. 51) and a new way of linking and synthesizing the past, present, and future: "[filling] out this spontaneous hearing of what is happening from moment to moment with something that incorporates both the past and the present [...] One must make some effort to listen backwards" (p. 52).

With regard to instinct and chaos, Adorno points out that 
the more that modern music abandons itself to unfettered instinctual impulses, the more it tends toward that intertwined, even chaotic state, then, if it is not to descend into a pre-artistic state, [it] requires organizing counterforces and conjures up out of itself the subtlest methods of formal construction [...] This can be grasped only by a musical consciousness that can keep up with the reciprocal interaction of these two aspects: that can be cognizant of the presence of instinctual impulse in formal construction and of the latter in the former. (1963a, p. 92)

This requires a differently structured consciousness than that of the entire Western tradition, which sees order on the one hand and chaos and instinct on the other as warring forces in a battle that can lead only to either domination by the subject or the subversion or annihilation of the subject. It also hearkens to the sort of restructuring of consciousness that occurs in psychoanalysis.

Taken together, Adorno's guidelines for listening hold out a model of experience, cognition, and action that bears more detailed exploration. The subject that can synthesize these elements and dimensions is not a traditional subject that has learned a new form of "music appreciation," a concept that Adorno detested and critiqued as part of musical commodity fetishism and the regression of listening (Adorno, 1963c), but rather a new subject whose identity is of a new type - as I suggested at the beginning - a type that can be gleaned from the structure of modern musical works themselves. To work out this new subject with any concreteness would require an important detour that would take us beyond the limits of the present paper: an exploration of the structures of subjectivity that both underlie and are created by the major composers of pre"modern" classical music: especially Bach, Mozart, and Beethoven, but also Wagner and Mahler. To understand the way in which works of modern music prefigure a new, non-schematic listener, we would have to first be somewhat clear both about the alienated consciousness of the contemporary listener that has been investigated so richly by Adorno as well as about the normative, ideally normal, "mature" listener.

There is a tendency among thinkers within the Marxian tradition, even those who have transcended the old dogmatic base/superstructure model, to assume that artistic creations and phenomena reflect forces within their 
sociohistorical context (despite great differences in how this relationship is conceived). Yet some other writers have suggested a different relationship, one in which it is first in art that forms and structures are worked out that only later, sometimes much later, come to predominate or even play a significant role in the surrounding culture and society, and this model is particularly relevant to Adorno's ideas about music listening as a kind of constitutive praxis. Herbert Read looks at the history of visual art as one in which artists take unconscious and preconscious material that exists within themselves and their fellow human beings and give it specific and graspable form which then becomes humanly accessible and eventually even sometimes commonplace (Read, 1965). A related claim is that of Harold Bloom, who asserts that

personality, in our sense, is a Shakespearean invention and is not only Shakespeare's greatest originality but also the cause of his perpetual pervasiveness. Insofar as we ourselves value, and deplore, our own personalities, we are the heirs of Falstaff and of Hamlet [...] (Bloom, 1998, p. 4).

Bloom argues that it is really Shakespeare who invented what has come in the

24 modern era to be thought of as the human - that the human psyche that is normative for modern culture is really Shakespeare's creation. It is possible to make such claims without being a complete idealist. A "materialist" version of this idea would be that certain emerging social processes and their implications are grasped in statu nascendi by the artist, writer, or composer and crystallized in forms that come to shape social life and human identity or personality. This indeed was Horkheimer's strategy in looking for precursors and prototypes of fascism in bourgeois social movements of the late Middle Ages and early modern period, or Horkheimer's and Adorno's in looking at Odysseus as prototype of the modern bourgeois. Indeed, I would argue that one can derive from Adorno's work the case that Beethoven is constitutive of the form of the modern bourgeois self. As Adorno writes, "Humanity in his [Beethoven's] work means: you should behave as this music behaves. It shows how to lead a life which is active, outwardly productive without being narrow - a life of solidarity" (1998, p.8). 
Analogously, his analysis of Schoenberg, Berg, and Webern leads to a normative construction of the modernist, post-modern identity.

One way to pursue this connection between musical structure and the structure of the self would be to explore concretely, with musical examples, the relationship between four things that are central to Adorno's thought about listening to modern music: the integration of past, present, and future in listening; the ability to hear identity in non-identity and vice versa; radical variation as the core technique of modern music; and the construction of personal identity. One could trace the evolution of musical variation from Bach and Mozart, through Beethoven, then Brahms, Elgar, and Mahler, and finally to Schoenberg and Webern, to demonstrate the assumptions contained in each of those composers' works - especially those that explicitly focus on theme and variations - about what constitutes identity. One would follow the gradual loosening of the structure of identity and of what counts as and is experienced as repetition, what as variation, and what as the underlying identity of the increasingly deviant and non-identical to the point of "radical variation", and what each means for the subjectivity and identity of the listening individual. One would hear the gradual disintegration and evaporation of the schemata and the surfacing of the subcutaneous - and accompanying that the disappearance of the work done for the listener by the schemata and, in consequence, the increasing demand on the listener to actively abandon herself to the immanent logic of the variation process in order to make the identity occur through, as Adorno says (explicitly using and referring to Kant's terminology in the Transcendental Deduction of the Categories in the Critique of Pure Reason), "a synthesis not through 'recognition in the concept' but rather through the simultaneously active and involuntary 'reproduction in the imagination'" (1963c, p. 36f.).

It seems quite significant in this context that Adorno refers back to these concepts from the first edition of Kant's Transcendental Deduction, because there (A 100-102) Kant establishes a clear link between the synthetic unity that occurs in appearances and the synthetic unity of the self. In the section on "The Synthesis of Reproduction in Imagination," Kant argues that "experience as such necessarily 
presupposes the reproducibility of appearances" (Kant, 1933[1781], p. 133). Kant points out that if I did not retain and reproduce in my single, unitary consciousness the previous representations in time of an object of experience while advancing to the subsequent representations, I would never obtain a complete representation, i.e. I would never experience it as an object. The connection to Adorno's statements about being able to connect the past and present in musical experience is obvious. In other words, for the listener to modern music, identity is not something given but something achieved only through active imaginative synthesis. The more that variations vary from the theme - the more "radical", in Adorno's language, variation becomes - the more active work is required to construct and maintain the identity, and this can be taken as paradigmatic for the conditions of personal identity in general in the contemporary world. In Adorno's words,

[modern music], too, does not fully dispense with the means of similarity, repetition, and identity. In so doing, it adapts to the insight of philosophy [Adorno really means here Hegel's Science of Logic, especially the section on "Essence" - JJS] that there is no non-identity without identity, nor the latter without the former. But in this music what is repeated, the identical, through its pure development also remains at the same time the nonidentical. Stated in musical, technical terms, its central technique is that of radical variation, even in - precisely in - the repetitions. The irrevocably returning sameness must always differentiate itself from its original form. (1963a, p. 50-51)

To take a few well-known musical examples, in Mozart's piano Variations on "Ah, vous dirais-je, Maman" (K. 265) the familiar nursery tune can be heard distinctly in almost every variation, as pure repetition, with the same notes and the same chords in the same or only slightly differing rhythm: with few exceptions, variation consists primarily of ornamentation laid on top of the tune. By contrast, it is possible, on first acquaintance, to listen to the last movement of Beethoven's Sonata in E major, op. 109 and hear the variations as separate pieces without hearing any identity or repetition whatsoever. Increasing immersion in the piece, however, with the active attention of which Adorno speaks, will make the identity shine through the apparent non-identity of the variations. Whether 
this occurs through intellectual reflection or through unconscious attention and receptivity, it manifests itself primarily in increasing perception of the work's beauty, integrity, and inner evolution. With Elgar's Enigma Variations for orchestra, there has been a century-long controversy about what the actual theme is that underlies the variations. That is, what unifies the variations is an underlying "essence" that is never directly stated. And when Webern guided the rehearsal of his Variations for Piano op. 27 by a pianist who kept on asking him to explain the underlying tone row on which the piece was based so that he could better understand it and therefore perform it better, Webern refused to tell him and forbade him to think about it, saying that it was irrelevant to the performance, which should be done in purely musical terms with a musician's intuition. Indeed a listener can move through a sheer act of attention and will from the state of not hearing the Webern piece as a set of variations at all to hearing all of it as variations. Adorno in his "Guidelines" examines in detail a particular instance of variation in one of Schoenberg's Five Pieces for Orchestra op. 16, to show the gradual transmutation of a pattern into something that is different but yet preserves a kind of continuity with the original pattern (1963a, p. 57-59). Inversely, in Morton Feldman's Coptic Light, what presents itself seems at first like pure repetition, like a passacaglia theme repeated over and over again, i.e. as pure identity, until, upon closer listening, the identity reveals itself as a fabric of subtle kaleidoscopic variation, as though identity studied under a microscope dissolved into a Brownian movement of consciousness.

It would be instructive, at the opposite end of the spectrum, to compare such subtle transmutation with the beat of much current popular music, where identity is maintained primarily through the simple repetition of a drum beat on every beat of every measure of a song, in such a way that everything on top of that beat is implicitly defined by it as, in essence, inessential - as though identity had swallowed up or drowned out any non-identity in the melody or the chord changes. For if they had substance, in the philosophical sense, they would not need an explicitly sounding beat behind them to constitute their inner coherence and identity. The agenda of this music is the beat. Indeed, the percussion blow on 
every beat is the purest musical expression of Adorno's "always the same" (das Immergleiche). This is underlined by the fact that the ability to maintain a beat seems to be a fundamental, species-specific competence of the human brain that differentiates human music from music-like characteristics of other animals: "the existence of measured music - music subject to an isochronous temporal pulse constitutes a quasi-universal" (Arom, 2000; see also Peretz and Hyde, 2003). In other words, human beings can hear and maintain a beat spontaneously, without it being literally spelled out for them. Indeed, much music lives from the interplay between the background, unplayed beat and the music's own rhythmic patterns. In the words of Anders Friberg and Johan Sundberg, "deviations [from the official] are an important part of musical expressivity" (1995, p. 2524). The constant playing of the beat eliminates such deviations and such interplay.

From such musical analyses we could then reflect on the evolution of types of personal identity and subjectivity, and see what we could learn from Adorno's "Guidelines" about ways to be and to not be, options for the constitution of meaningful subjectivity or identity, and what directions we would choose for ourselves to have maximally meaningful lives in a world that has ceased to provide us with the categories of unity in happiness.

I mentioned in my presentation of subsidiary claims that Adorno's explicit theory of listening, which he terms "structural listening", is itself inadequate to his implicit theory of listening as contained in the practice of his actual musical writings or its presuppositions. For it captures only one or two dimensions of a much more multidimensional approach for which "structural" is not the most apt term: an approach that is clearly manifested in his own way of listening to and experiencing music. In a way, one can make of Adorno's analyses the same sort of reproach that Hegel made of Kant, namely that Kant could not account for his own theory by means of his theory and that a higher-level, more reflective kind of theory was necessary in order to do so. I call attention to this because ultimately one would need such a higher level, self-reflective, multidimensional theory of music listening and of musical analysis in order to bring to 
fulfillment what is clearly Adorno's ultimate intention in his musical work, as manifested in his most concrete and fully worked out musical analyses.

For example, in the "Guidelines", a fair amount of the actual musical analysis consists of motivic analysis, showing how musical motifs are either elaborated, varied, or broken down into their component parts. It is true that Adorno often uses such motivic analysis to move to a more phenomenological description of the music so analyzed, as when he shows how Berg produces a sense of temporal stagnation or quiescence through the breaking down of the initial motif of a string quartet movement into its component parts. At the same time, some of Adorno's true greatness as a listener who is also an analyst, theorist, and historian is expressed in metaphorical descriptions that are not even explained in terms of such motivic analysis, as represented, for example, in his already quoted description of the last movement of the Das Lied von der Erde as providing a view of the earth in its smallness like that seen by astronauts from space.

Perhaps Adorno's greatest gift was indeed the way in which he listened to music, which underlay not only his many and important musical writings but can be argued to have been an important basis of his philosophy of history and theory of society in general. His interpretations of music are not the result of the application to music of an external body of theory. Rather they are a way of hearing and experiencing the music, into which of course theory had entered and with which it has been mediated. And this way of hearing and experiencing music was also for Adorno a way of disclosing the world. Indeed, his ability to articulate truth about society, history, and humanity can be seen as an extension of his ability to formulate what a piece of music is, the truth about music. And it is not surprising that the available music-analytic and music-hermeneutic tools, concepts, and schemata available to him were not adequate to his own way of hearing. Indeed, his expositions about music listening - such as his description of "structural hearing" or his typology of listeners in his Introduction to the Sociology of Music (Adorno, 1988) are remarkably impoverished, ahistorical, and undialectical compared to the subtlety and complexity of his own way of hearing, which does not at all fit into such categories as structural hearing or "expert 
listener". Indeed, the "expert listener" that Adorno appears to define as normative and paradigmatic in the sociology of music book seems almost devoid of experience and rather like something that could be instantiated by a computer program. The category is defined primarily in technical, not aesthetic or experiential terms. Without focusing on hearing per se, Max Paddison makes the parallel point that Adorno's theory of music and musical history is not adequate to his own analyses (Paddison, 1993).

But it is possible to identify and abstract features of Adorno's hearing from his varied writing and comments about music in general and specific pieces of music. And this is an urgent task, for two related reasons. First, to resist the fetishism of music, the regression of hearing, and the power of the cultural industry to produce a schematic, repetitive, one-dimensional experience, it is not enough to provide it with an intellectual critique. This does not transmit the ability to hear to those who do not already possess it and who need it. Rather it is important to set against these forces an actual model of hearing and listening to music that is experientially rich, dialectically complex, and personally forceful - a model that can actually help people hear authentic music and hear music authentically, although it is important to consider whether this model is historically viable at present. Second, this is precisely the area where Adorno is our greatest potential teacher, if we know what it is that we can learn from him. It would be wasteful of the resources of Adorno and the critical tradition not to learn what he can teach us as an experiential mentor and not just as a formulator of theory.

Some of Adorno's characteristics as a listener were his ability to hear simultaneously the total structure and each particular moment; to hear historically, hearing the piece as mediated by its context and the universality in that context; to hear the potentialities inherent in the music of a particular time, hearing the difference between, for example, the progressive and reactionary options historically available; to hear the dialectical mediation of the ideal on the one hand and the material, emotional, biological, subcutaneous on the other; to hear literally and metaphorically at the same time, and to be able to articulate the meanings in language; to know how to draw on one's own private associations 
and experiences and either make them universal or find what's universal in them, rather than dissolving the music into those associations and experiences; to hear redemptively (which also means compassionately); to hear the dialectic between formal features of music, e.g. harmonic structures, and material-historicalexpressive features; to hear with the Hegelian method of "reines Zusehen" ("pure seeing" or "pure looking at"), which unfolds what is really there rather than bringing something to it from the outside; to hear in terms of the messianic history of culture that he shares with Benjamin and Marcuse, of experiencing and understanding the uniqueness of each historical moment and how these moments structure the culture that surrounds them and rise out of them. Each of these aspects would need to be developed more explicitly, and with examples, in another context. Developing a model of how Adorno heard music would also be useful beyond the domain of music itself, in the whole arena of developing a more fertile interaction between dialectical experience and dialectical thinking.

Articulating how Adorno heard or listened to music would be a fitting way to render homage to him in a way that acknowledged and paid tribute to something that was as much a highly personal, individual gift as an intellectual and cultural resource. It would be paying attention to his own "subcutaneous" sphere of life and his own individuation as a person.

\section{Reference List}

ADDIS, Laird. Of Mind and Music. Ithaca: Cornell University Press, 1999.

ADORNO, Theodor W. Minima Moralia: Reflections from Damaged Life. Trans. Edmund Jephcott. London: NLB, (1974) [1951].

Anweisungen zum Hőren neuer Musik. In: ADORNO, Theodor W. Der Getreue Korrepetitor: Lehrschriften Zur Musikalischen Praxis. Frankfurt: S. Fischer Verlag, 1963a.

. Der Getreue Korrepetitor: Lehrschriften Zur Musikalischen Praxis. Frankfurt: S. Fischer Verlag, 1963b.

. Die Gewürdigte Musik. In: ADORNO, Theodor W. Der Getreue Korrepetitor:

Lehrschriften Zur Musikalischen Praxis. Frankfurt: S. Fischer Verlag, 1963c.

Negative Dialektik. Frankfurt am Main: Suhrkamp Verlag, 1970. 
Das Erbe und Die Neue Musik. In: ADORNO, Theodor W. Musikalische Schriften V. Frankfurt am Main: Suhrkamp Verlag, 1984.

. Introduction to the Sociology of Music. New York: Continuum, 1988.

. Mahler: A Musical Physiognomy. Trans. Edmund Jephcott. Chicago: University of Chicago Press, 1992a.

. Mahler. In: ADORNO, Theodor W. Quasi Una Fantasia: Essays on Music \& Culture. Trans. Rodney Livingstone. New York: W. W. Norton and Company, 1992b.

. Music and Language: A Fragment. In: Quasi Una Fantasia: Essays on Music \& Culture. Trans. Rodney Livingstone. New York: W. W. Norton and Company, 1992c.

. Vers une Musique Informelle. In: Quasi Una Fantasia: Essays on Music \& Culture. Trans. Rodney Livingstone. New York: W. W. Norton and Company, 1992d.

. Beethoven: The Philosophy of Music. TIEDEMANN, Rolf (Ed.); JEPHCOTT, Edmund (Trans.). Stanford: Stanford University Press, 1998.

AROM, Simha. Prolegomena to a Biomusicology. In: WALLIN, Nils L.; MERKER, Björn; BROWN, Steven (Eds.). The Origins of Music. Cambridge, Mass.: The MIT Press, 2000.

BLOOM, Harold. Shakespeare: The Invention of the Human. New York: Riverhead Books, 1998.

BROWN, Steven. The "Musilanguage" Model of Music Evolution. In: WALLIN, Nils L.; MERKER, Björn; BROWN, Steven (Eds.). The Origins of Music. Cambridge, Mass.: The MIT Press, 2000.

CLARKE, Eric F. Ways of Listening: An Ecological Approach to the Perception of Musical Meaning. New York: Oxford University Press. 2005.

CLIFTON, Thomas. Music as Heard: A Study in Applied Phenomenology. New Haven: Yale

32 University Press, 1983.

COOK, Nicholas. Music, Imagination, and Culture. New York: Oxford University Press, 1990.

CROSS, Ian. Music and Biocultural Evolution. In: CLAYTON, Martin; HERBERT, Trevor; MIDDLETON, Richard (Eds.). The Cultural Study of Music: A Critical Introduction. New York: Routledge, 2003.

DENORA, Tia. After Adorno: Rethinking Musical Sociology. Cambridge: Cambridge University Press, 2003.

. Music in Everyday Life. Cambridge: Cambridge University Press, 2000.

FRIBERG, Anders; SUNDBERG, Johan. Time Discrimination in a Monotonic, Isochronous Sequence. Journal of the Acoustical Society of America, v. 98, n. 5, 1995.

HABERMAS, Jürgen. Knowledge and Human Interests. Trans. Jeremy J. Shapiro. Boston: Beacon Press, 1971.

JANKÉLÉVITCH, Vladimir. Music and the Ineffable. Trans. Carolyn Abbate. Princeton: Princeton University Press, 2003.

KANT, Immanuel. Critique of Pure Reason. Trans. Norman Kemp Smith. London: Macmillan and Company, (1933) [1781]. 
KRAMER, Lawrence. Subjectivity Rampant! Music, Hermeneutics, and History. In: CLAYTON, Martin; HERBERT, Trevor; MIDDLETON, Richard (Eds.). The Cultural Study of Music: A Critical Introduction. New York: Routledge, 2003.

LEPPERT, Richard. Introduction. In: LEPPERT, Richard (Ed.); GILLESPIE, Susan H. (Trans.); ADORNO, Theodor W. Essays on Music. Berkeley: University of California Press, 2002.

LANGER, Suzanne K. Feeling and Form: A Theory of Art. New York: Charles Scribner's Sons, 1953.

LEVIN, David Michael. The Listening Self: Personal Growth, Social Change, and the Closure of Metaphysics. London: Routledge, 1989.

MARX, Karl. Grundrisse der Kritik der politischen Ökonomie (Rohentwurf), 1857-1858. Berlin: Dietz, (1953) [1858].

MENDELSSOHN Bartholdy, Paul; MENDELSSOHN Bartholdy, Carl (Eds.) Briefe aus den Jahren 1830 bis 1847 von Felix Mendelssohn Bartholdy. Leipzig: Hermann Mendelssohn, 1878.

MITHEN, Steven. The Singing Neanderthals: The Origins of Music, Language, Mind and Body. London: Weidenfeld \& Nicolson, 2005.

NANCY, Jean-Luc. Listening. Trans. Charlotte Mandell. New York: Fordham University Press, 2002.

NICHOLSEN, Shierry Weber. Exact Imagination, Late Work: On Adorno's Aesthetics. Cambridge: MIT Press, 1997.

PADDISON, Max. Adorno's Aesthetics of Music. Cambridge: Cambridge University Press, 1993.

PERETZ, Isabelle; HYDE, Krista L. What Is Specific to Music Processing? Insights from Congenital Amusia. TRENDS in Cognitive Sciences, v. 7, n. 8, p. 362-367, 2003.

READ, Herbert. Icon and Idea: The Function of Art in the Development of Human Consciousness. New York: Schocken, 1965.

ROUSSEAU, Jean-Jacques. Essay on the Origin of Languages Which Treats of Melody and Musical Imitation. In: MORAN, John H; GODE, Alexander (Eds.). On the Origin of Language. Chicago: University of Chicago Press. (1986) [1781]. p. 1-74.

SCHOPENHAUER, Arthur. Die Welt als Wille und Vorstellung. In: GRISEBACH, Eduard (Ed.). Schopenhauer's Sämmtliche Werke in Fünf Bänden. Leipzig: Inselverlag, [n.d.] [1859]. v. I.

SHEPHERD, John; WICKE, Peter. Music and Cultural Theory. Cambridge: Polity Press, 1997.

Jeremy J. Shapiro: jshapiro@fielding.edu

Artigo recebido e aprovado em 04/12/2010 